\title{
Pengembangan Materi Allah Pencipta Alam Semesta Pada Pembelajaran PAI dengan Eksperimen Sains di SD Muhammadiyah Bayen
}

\author{
Rafika Dwi Rahmah MZ \\ Universitas Ahmad Dahlan \\ Email: rafikadrmz1605@gmail.com
}

\begin{abstract}
Problems that occur at SD Muhammadiyah Bayen based on interviews and observations that have been made are learning that takes place not by the objectives of the 2013 curriculum which emphasizes integration between subjects and students have difficulty in remembering the lessons that have been explained by the teacher. So the purpose of this research is as an effort to overcome the problems that occur at SD Muhammadiyah Bayen by integrating the material of God the Creator of the Universe in the learning of Islamic Education using scientific experimental methods that are generally used in Natural Sciences subjects. The research method used is a combination of field research and descriptive qualitative type of library studies. The use of experimental methods in previous studies shows that the experimental method can increase the affective, cognitive and psychomotor aspects of students. The results of this combination research are the need for integration between Islamic religious education and other subjects so that children become more familiar with the concept of religious material as a whole and not dogmatic and students can remember the material with the help of experiments that they will do themselves.
\end{abstract}

Keywords: Islamic Religious Education, Experimentation, Science, Integration.

\section{Pendahuluan}

Pada kurikulum 2013 semua mata pelajaran wajib berkontribusi terhadap pembentukan aspek afektif, psikomotorik dan kognitif peserta didik serta menuntut agar pembelajaran di kelas berjalan dengan aktif. ${ }^{1}$ Berdasarkan data hasil mini research yang telah dilakukan di SD Muhammadiyah Bayen, pembelajaran agama islam berlansung secara aktif ${ }^{2}$ tetapi integrasi antara pendidikan agama islam dan mata pelajaran lainnya dapat dinilai kurang sehingga penerapan dari kurikulum 2013 belum secara maksimal tercapai. ${ }^{3}$ Selain permasalahan tersebut, siswa cenderung mudah lupa tentang materi pembelajaran yang disampaikan sehingga guru selalu berulang-ulang dalam menyampaikan materi kepada siswa. ${ }^{4}$

Padahal integrasi pembelajaran agama islam dengan mata pelajaran lain penting dilakukan agar terciptanya generasi muda yang berilmu, beriman dan

1 Artikel Publikasi Universitas Negeri Medan oleh: Pardomuan Nauli Josip Mario Sinambela. Kurikulum 2013 dan Implementasinya dalam Pembelajaran. 2013, 17.

2 Hasil wawancara dengan guru pendidikan agama islam (Rifatul Khairiyah, S.Ag) pada Kamis, 02 Mei 2019 di Ruang guru SD Muhammadiyah Bayen, Pukul 10.00 WIB

${ }_{3}^{3}$ Peraturan Menteri Pendidikan dan Kebudayaan Republik Indonesia nomor 66 tahun 2013 tentang Standar Penilaian Pendidikan.

4 Hasil wawancara dengan guru pendidikan agama islam (Rifatul Khairiyah, S.Ag) pada Kamis, 02 Mei 2019 di Ruang guru SD Muhammadiyah Bayen, Pukul 10.00 WIB 
berakhlak mulia. ${ }^{5}$ Banyak dari orang berilmu yang jauh dari agama dan sebaliknya kalangan agamis yang jauh dari ilmu dunia. ${ }^{6}$ Hal tersebut tidak sesuai dengan apa yang telah Allah contohkan dengan mengutus Nabi dan Rasul yang pandai dalam ilmu dunia dan Agama yang berjalan selaras.

Walaupun siswa aktif dalam pembelajaran, terkadang siswa cenderung melupakan materi pembelajaran. Indikasi dari permasalahan tersebut adalah kurangnya metode pembelajaran yang merangsang pikiran siswa sehingga hasil dan materi pembelajaran yang berlangsung dapat tertanam.

Upaya dalam menanggulangi masalah-masalah tersebut dapat dilakukan dengan cara mengintegrasi mata pelajaran pendidikan agama islam dengan salah satu mata pelajaran lainnya yang cukup berhubungan dengan materi pembelajaran. ${ }^{7}$ Peneliti mengambil materi pembelajaran Kelas 4 Bab 2 Beriman Kepada Allah dan Rasulnya. ${ }^{8}$ Pada Bab 2 memuat tentang Allah itu ada dan Allah itu pencipta alam semesta. Materi pembelajaran tersebut akan diintegrasikan dengan pembelajaran dan eksperimen sains menggunakan koin dan kertas yang bergambar garis edar planet.

Metode eksperimen adalah metode yang cukup baik dalam meningkatkan rasa keingintahuan siswa sehingga siswa dapat dengan antusias dalam mengikuti pembelajaran dan umumnya percobaan eksperimen akan selalu diingat oleh siswa karena siswa melakukan percobaan secara individu. ${ }^{9}$ Menurut Roestiyah metode eksperimen adalah suatu cara mengajar, dimana siswa melakukan suatu percobaan tentang suatu hal, mengamati prosesnya serta menuliskan hasil percobaannya, dan hasil pengamatan itu disampaikan ke kelas dan dievaluasi oleh guru. ${ }^{10}$ Metode eksperimen digunakan berdasarkan dari suatu masalah yang perlu dipecahkan kemudian dalam prosedur kerjanya berpegang pada prinsip ilmiah. ${ }^{11}$

Menurut Sugiyono metode eksperimen terdapat 4 jenis penelitian, yaitu: 1. Preexperimental designs, 2. Try-Experimental design, 3. Factorial Design, 4. Quasi Experimental Design. ${ }^{12}$ Pada penelitian yang akan dilakukan dalam mengevaluasi metode eksperimen yang peneliti sarankan dapat menggunakan salah satu desain penelitian pre-eksperimen designs yaitu one-shot case study..$^{13}$ Desain penelitian ini mengarahkan treatment terhadap

${ }^{5}$ Nandang Kosim. Pengembangan dan Aplikasi Pembelajaran PAI di SD: Nandang Kosim. Vol. 2 No. 2 Tahun 2015, 122.

${ }^{6}$ Jalaluddin Rahmad. Psikologi Agama sebuah Pengantar, 28.

${ }^{7}$ Dr. H. Farid Hasyim., MA. Kurikulum Pendidikan Agama Islam: Filosofi Pengembangan Kurikulum Transformatif antara KTSP dan Kurikulum 2013. Malang: Madani 2015, 82-83

8 Buku Silabus dan Rencana Pelaksanaan Pembelajaran (RPP) Kelas 4 semester 1 SD Muhammadiyah Bayen, guru PAI (Rifatul Khairiyah, S.Ag)

${ }^{9}$ Al-Farisi. Startegi Pembelajaran. 2005, 2.

10 Trianto. Mendesain Model Pembelajaran Inovatif-Progresif. Ed ke 4. 2010, 23.

${ }^{11}$ Hayat, M. S., S. Anggraeni, \& S. Redjeki. Pembelajaran berbasis praktikum pada konsep invertebrata untuk pengembangan sikap ilmiah siswa. Jurnal Bioma, Vol. 1 No. 2 tahun 2011, 15.

12 Sugiyono. Metode Penelitian Pendidikan Pendekatan Kuantitatif, kualitatif, dan R\&D. $2010,93$. 2016,88

13 Aneng Dewi Saputri. Integrasi Tembang Pocung. Physics Education Journal Vol 5 No 2 
suatu kelompok kemudian diobservasi hasil dari treatment. Hasil treatment adalah sebagai variable independent dan hasil adalah sebagai variable dependent. Dalam eksperimen ini subjek disajikan dengan beberapa jenis perlakuan lalu diukur hasilnya. ${ }^{14}$

Artikel ini akan memaparkan bagaimana konsep pembelajaran materi Allah pencipta alam semesta dengan eksperimen sains menggunakan kajian literatur review.

\section{Metode Penelitian}

Penelitian pada artikel ini adalah kombinasi antara penelitian lapangan serta literatur karena data yang disajikan pada artikel ini berdasarkan observasi, wawancara dan survei yang telah dilakukan sebelumnya dengan guru mata pelajaran pendidikan agama islam di SD Muhammadiyah Bayen. Pengolahan data yang akan dilakukan dalam penelitian ini adalah analisis deskriptif kualitatif.

\section{Prosedur Kegiatan}

Sebelum melakukan penelitian, tahap pertama yang dilakukan adalah observasi, wawanara dan survei seberapa paham dan pengetahuan guru-guru serta siswa dan melihat sarana prasarana memadai atau tidak. Obeservasi, wawancara dan survei dilakukan untuk mencari permasalahan-permasalahan yang dihadapai oleh siswa kelas 4 maupun guru pengampu di SD Muhammadiyah Bayen tentang materi Allah pencipta alam semesta dalam bab 2 yang juga sebagai subjek penelitian dan hasil tersebut digunakan juga sebagai sarana dalam mengumpulkan data dengan model interaktif. Tahap kedua adalah pelaksanaan pembelajaran dengan eksperimen. Pada tahap kedua memaparkan materi melakukan eksperimen, berdiskusi dengan siswa dan mencapai kesimpulan pembelajaran. Tahap ketiga adalah tahap evaluasi yang berdasarkan pengumpulan data pada tahap kedua. ${ }^{15}$

\section{Alat dan Bahan Eksperimen}

Alat dan bahan yang dibutuhkan dalam eksperimen pembelajaran, yaitu:

Tabel 1.

\begin{tabular}{cll}
\multicolumn{3}{c}{ Alat Percobaan } \\
\hline No. & \multicolumn{1}{c}{ Alat } & Jumlah \\
\hline 1. & Pulpen & 1 Buah \\
\hline 2. & Kertas & 1 Buah \\
\hline
\end{tabular}

${ }^{14}$ Nur Lindah Aisyah dan Luthfiyah Nurlaela. Penerapan Model Pembelajaran Kooperatif Tipe Make a Match Untuk Meningkatkan Hasil Belajar Siswa Kelas X Jasa Boga Pada Kompetensi Dasar Potongan Bahan Makanan Di SMK Negeri 11 Cerme, Gersik. Vol 4 No 1. 2015,143-144.

${ }^{15}$ M. Qurbaniah dan N. Awaliyah. Eksperimen Sains Berbasis Kreasi Warna Alami Sebagai Inovasi dalam Pembelajaran Biologi. Vol 1 2018, 94 
Tabel 2.

Bahan Percobaan

\begin{tabular}{ccc}
\hline No. & Bahan & Jumlah \\
\hline 1. & Uang Koin & 10 Buah \\
\hline
\end{tabular}

\section{Cara Kerja}

1. Menyiapkan alat dan bahan

2. Menggambar garis edar planet dengan pulpen pada kertas

3. Menggetos 10 buah koin menggunakan tangan

4. Menjatuhkan koin-koin pada kertas yang bergambar garis edar planet secara berulang sebanyak 10 kali

5. Mengamati koin pada tiap pengetosan

6. Menganalisis sisi koin yang muncul dan mencatat.

7. Membuat kesimpulan.

\section{Spesifikasi Alat dan Bahan}

Kertas bergambar garis edar planet dan uang koin dimaksudkan sebagai simulai dari bigbang teori yang diyakini secara sains sebagai awal mula terbentuknya alam semesta. Tujuan pengetosan dilakukan untuk melihat apakah dengan 10 kali percobaan tersebut dapat dengan sempurna tertatanya koin dan sisi koin menghadap ke arah yang sama seperti saat ledakan bigbang terjadi sehingga alam semesta dapat tersusun seara sempurna dan saling berkaitan.

\section{Hasil dan Pembahasan}

\section{Integrasi Mata Pelajaran di Kurikulum 2013}

Pada ajaran agama Islam manusia ditugaskan sebagai khalifah di bumi yang menjaga bumi serta isinya maka syariat Islam mendorong manusia untuk mempelajari ilmu lain seperti sains, ekonomi, dan sosial sehingga manusia dapat membangun, membina bahkan mengatur peradaban sesuai dengan ajaran agama Islam. ${ }^{16}$

Banyak orang beranggapan bahwa agama tidak boleh/cocok dicampur adukkan dengan ilmu lainnya. Hal ini terjadi karena pendapat berbagai ilmuan tentang sains erat kaitannya dengan pengalaman yang abstrak dan bersifat deskriptif sedangkan agama lebih terkait dengan pengalaman kehidupan preskriptif. ${ }^{17}$

Mata pelajaran sains dan pendidikan agama islam seharusnya berjalan selaras dan tidak tumpang tindih apalagi saling bertolak belakang pasalnya Agama Islam adalah agama yang sangat menjungjung tinggi ilmu, baik ilmu akhirat maupun ilmu dunia. ${ }^{18}$ Sebagai contoh Nabi Isa a.s adalah seorang Nabi dan tidak diragukan lagi ilmu

\footnotetext{
${ }^{16}$ Marimba Ahmad D, Filsafat Pendidikan Islam.1984

${ }^{17}$ Samsul Nizar, Filsafat Pendidikan Islam Pendekatan Historis, Teoritis, Dan Praktis. 2002, $41-42$.

${ }^{18}$ Sudarmojo Agus Haryo, Menyibak Rahasia Sains Bumi dalam Al-Qur’an, 2008.
} 
akhiratnya tetapi dilain sisi Nabi Isa terkenal dengan kemahirannya dalam menyembuhkan penyakit pada masa itu yang berarti Nabi Isa juga mempelajari ilmu kedokteran dan Nabi Nuh a.s yang dapat merancang serta membuat kapal terhebat pada masanya serta memiliki ilmu agama yang baik. ${ }^{19}$ Dengan integrasi mata pelajaran agar tujuan pada kurikulum 2013 dapat terapai.

Khudori Sholeh menyatakan bahwa Lembaga pendidikan Islam telah melakukan integrasi dengan ilmu lainnya dengan memberikan materi seperti fiqh, tafsir dan ainnya dan dikembangkan dengan disiplin ilmu lainnya. ${ }^{20}$ Integrasi yang dilakukan hanya sebatas ceramah ilmu agama dan secara umum bersama-sama tapi tanpa saling mengaitkan karena berdasarkan filosofis yang berakibat siswa tidak mendapatkan pemahaman yang utuh dan komprehensif. ${ }^{21}$

Peneliti berpendapat bahwa integrasi yang telah dilakukan belum tepat sasaran seperti tujuan dari kurikulum 2013. Dengan kemajuan zaman yang pesat ini siswa menjadi lebih kritis dalam menyikapi sesuatu sehingga terkadang mereka tidak menerima pelajaran pendidikan agama Islam secara baik, seperti ketika materi tentang halal dan haram siswa tidak dengan mudah memahami batasan mengapa ada yang diharamkan dan mereka akan memikirkan pertanyaan-pertanyaan dikepala mereka. ${ }^{22}$ Dalam menjawab kasus tersebut ilmu sains mampu memberikan penjelasan yang sesuai dengan logika dan nalarnya. Sehingga menekankan pentingnya integrasi antara pendidikan agama Islam dan ilmu lainnya agar dapat saling mendukung terbentuknya siswa yang ebrilmu dan berakhlak mulia.

\section{Metode Eksperimen pada Pembelajaran}

Eksperimen pada penelitian ini bertujuan sebagai pembuktian secara logika bahwa alam semesta tercipta bukan dengan tidak sengaja tetapi Allah mencipta alam semesta dengan segala kesempurnaan-Nya dengan tujuan yang pasti karena tidak mungkin sesuatu terjadi secara tiba-tiba dengan peluang yang kecil sehingga didapatkan kesimpulan bahwa pencipta itu nyata. Selain dari eksperimen tersebut akan banyak menjelaskan logika secara mikro tentang dan bagaimana bukti bahwa Allah itu pencipta dan Allah itu ada.

Umumnya pelaksanaan metode eksperimen sains pada pembelajaran agama islam belum pernah dilakukan sehingga data nyata dari hasi penelitian metode tersebut tidak dapat ditampilkan tetapi berkaca dari keberhasilan oleh hasil penelitian pembelajaran menggunakan eksperimen sains dapat membuktikan bahwa dengan metode eksperimen pembelajaran siswa dapat mengingat materi dan hasil belajar

19 Abdurrahman R Effendi dan Gina Puspita,Membangun Sains dan Teknologi Menurut Kehendak Tuhan, 2007

${ }^{20}$ Hasbullah, Sejarah Pendidikan Islam di Indonesia: Lintasan Sejarah Pertumbuhan dan Perkembangan, 1999,

${ }^{21}$ Muhaimin, Pemikiran dan Aktualisasi Pengembangan Pendidikan Islam, 2011 $2014,126-128$

22 A. Rusdiana. Integrasi Pendidikan Agama Islam dengan Sains dan Teknologi. Vol 8 No 2 
karena siswa melakukan percobaan sendiri, berdiskusi serta menyimpulkan apa yang diperoleh dari eksperimen tersebut. ${ }^{23}$ Penjabaran hasil pembelajaran tersebut dibuktikan dengan penelitian yang dilakukan oleh D. Rahmawati, Nugroho dan Putra (2014) yang menyimpulkan bahwa pembelajaran dengan metode eksperimen bedampak positif siswa lebih aktif dan mengingat hasil belajar dengan menganalisis hasil pretes dan postes yang dilakukan pada penelitian tersebut. ${ }^{24}$ Peneliti yang lain seperti Rina, Widha dan Suciati (2012) mempublikasikan dalam artikel penelitian mereka bahwa metode eksperimen dapat meningkatkan afektif, kognitif dan psikomotorik siswa berdasarkan data-data hasil penelitian mereka. ${ }^{25}$

\section{Catatan Akhir}

Pentingnya integrasi mata pelajaran lain dengan pendidikan agama merupakan langkah awal sebagai memperluas pemikirian siswa sehingga taraf kehidupan dunia dan akhiratnya dapat meningkat dan terarah sesuai dengan ajaran agama Islam.

Kedepannya integrasi antara pembelajaran sains dan pendidikan agama islam dapat saling melengkapi sehingga siswa mudah dalam memahami, menghayati kita suci Al-Quran dan Hadist baik secara pemahaman akal tapi juga jiwa melalui pembelajaran, latihan, serta penggunaan metode yang baik agar tujuan pembelajaran pendidikan agama Islam sesungguhnya dapat terapai dan siswa menjadi manusia yangberakhlak mulia dalam mengamalkan ajaran agama islam.

\section{Daftar Rujukan}

A. Rusdiana. Integrasi Pendidikan Agama Islam dengan Sains dan Teknologi. Vol 8 No 2 2014, 126-128

Abdurrahman R Effendi dan Gina Puspita. Membangun Sains dan Teknologi Menurut Kehendak Tuban, Jakarta: Giliran Timur. 2007

Al-Farisi. Startegi Pembelajaran. Jakarta: Rajawali Pres 2005, 2.

Aneng Dewi Saputri. Integrasi Tembang Pocung dalam Pembelajaran Kooperatif Tebak. Kata Pada Tema Alat Optik untuk. Mendeskripsika Sikap Ilmiah dan Motivasi Belajar Siswa. Physics Education Journal. Vol 5 No 2 2016, 88

Artikel Publikasi Universitas Negeri Medan oleh: Pardomuan Nauli Josip Mario Sinambela. Kurikulum 2013 dan Implementasinya dalam Pembelajaran. 2013, 17.

Buku Silabus dan Rencana Pelaksanaan Pembelajaran (RPP) Kelas 4 semester 1 SD Muhammadiyah Bayen, guru Pendidikan Agama Islam (Rifatul Khairiyah, S.Ag)

${ }^{23}$ Umah, S.K., Sudarmin, N. R. Dewi. Pengembangan Petunjuk Praktikum IPA Terpadu Berbasis Inkuiri Terbimbing pada Tema Makanan dan Kesehatan. Unnes Science Education Journal: 3(2). 2014

${ }^{24}$ D. Rahmawati, S.E. Nugroho, N.M.D. Putra Penerapan Model Pembelajaran Kooperatif Tipe NHT Berbasis Eksperimen Untuk Meningkatkan Keterampilan Proses Sains Siswa SMP. Vol 3 No 1 2014, 44.

${ }^{25}$ Rina Asuti, Widha Sunarno dan Suciati Sudarisman. Pembelajaran IPA dengan Pendekatan Keterampilan Proses Sains Menggunakan Metode Eksperimen Bebas Termodifikasi dan Eksperimen Terbimbing Ditinjau dari Sikap Ilmiah dan Motivasi Belajar Siswa. Vol 1 No 1 2012, 54-59 
D. Rahmawati, S.E. Nugroho, N.M.D. Putra Penerapan Model Pembelajaran Kooperatif Tipe NHT Berbasis Ekesperimen Untuk Meningkatkan Keterampilan Proses Sains Siswa SMP. Vol 3 No 1 2014, 44.

Dr. H. Farid Hasyim., MA. Kurikulum Pendidikan Agama Islam: Filosofi Pengembangan Kurikulum Transformatif antara KTSP dan Kurikulum 2013. Malang: Madani 2015, 82-83

Hasbullah. Sejarah Pendidikan Islam di Indonesia: Lintasan Sejarah Pertumbuban dan Perkembangan. Jakarta: RajaGrafindo, 1999, cet. ke-3

Hasil wawancara dengan guru pendidikan agama islam (Rifatul Khairiyah, S.Ag) pada Kamis, 02 Mei 2019 di Ruang guru SD Muhammadiyah Bayen, Pukul 10.00 WIB

Hayat, M. S., S. Anggraeni, \& S. Redjeki. Pembelajaran berbasis praktikum pada konsep invertebrata untuk pengembangan sikap ilmiah siswa. Jurnal Bioma, Vol. 1 No. 2 tahun 2011, 15.

Jalaluddin Rahmad. Psikologi Agama sebuah Pengantar. (Bandung: Mizan, 2003), 28.

M. Qurbaniah dan N. Awaliyah. Eksperimen Sains Berbasis Kreasi Warna Alami Sebagai Inovasi dalam Pembelajaran Biologi. Vol 1 2018, 94

Marimba Ahmad D. Filsafat Pendidikan Islam. Bandung: PT. Al-Maarif,1984

Muhaimin. Pemikiran dan Aktualisasi Pengembangan Pendidikan Islam. Jakarta: Rajawali Pers, 2011

Nandang Kosim. Pengembangan dan Aplikasi Pembelajaran PAI di SD: Nandang Kosim. Vol. 2 No. 2 Tahun 2015, 122.

Nur Lindah Aisyah dan Luthfiyah Nurlaela. Penerapan Model Pembelajaran Kooperatif Tipe Make a Match Untuk Meningkatkan Hasil Belajar Siswa Kelas X Jasa Boga Pada Kompetensi Dasar Potongan Bahan Makanan Di SMK Negeri 11 Cerme, Gersik. Vol 4 No 1. 2015,143-144.

Peraturan Menteri Pendidikan dan Kebudayaan Republik Indonesia nomor 66 tahun 2013 tentang Standar Penilaian Pendidikan.

Rina Asuti, Widha Sunarno dan Suciati Sudarisman. Pembelajaran IPA dengan Pendekatan Keterampilan Proses Sains Menggunakan Metode Eksperimen Bebas Termodifikasi dan Eksperimen Terbimbing Ditinjau dari Sikap Ilmiah dan Motivasi Belajar Siswa. Vol 1 No 1 2012, 54-59

Trianto. Mendesain Model Pembelajaran Inovatif-Progresif. Ed ke 4. Jakarta: Kencana 2010, 23.

Samsul Nizar. Filsafat Pendidikan Islam Pendekatan Historis, Teoritis, Dan Praktis. Jakarta: Ciputat Pers. 2002, 41-42.

Sudarmojo Agus Haryo. Menyibak Rabasia Sains Bumi dalam Al-Qur'an. Bandung: Mizan Pustaka, 2008.

Sugiyono. Metode Penelitian Pendidikan Pendekatan Kuantitatif, kualitatif, dan R\&D. Bandung: Alfabeta 2010, 93.

Umah, S.K., Sudarmin, N. R. Dewi. Pengembangan Petunjuk Praktikum IPA Terpadu Berbasis Inkuiri Terbimbing pada Tema Makanan dan Kesehatan. Unnes Science Education Journal: 3(2). 2014 